We understand why the new intellectual aptitude tests are being introduced, but are concerned that they are being introduced uncritically and without published evidence on their reliability and validity. Typically, they involve only an hour or two of testing time and are thus unlikely to have high reliability or generalisability (particularly owing to content specificity), although no data have been published. Their validity can be doubted for good reason, as published studies have found that intellectual aptitude compares poorly with A levels in predicting the outcome of university and medical school, and it has not been shown to add value to the selection process.

The appropriate alternative to refining A level grades would be for the medical schools to commission a new test, reliably assessing high grade scientific knowledge and understanding. At the same time, more research into the value of non-cognitive tests is clearly important and required.

We accept that our criticism of intellectual aptitude tests could be shown to be misplaced when the medical schools using them publish their evidence on predictive validity and reliability. Currently the tests are being justified, not by means of any reported data but by general assertions of organisational quality, unspecified relations between scores and university examinations, and by the observation that admissions staff are using them..$^{25}$ Without evidence, medical schools using these tests are vulnerable to legal challenge.

We thank the referees and William James and Chris Whetton for help with preparing this paper.

Contributors: DAP and ICM conceived the article. ICM wrote the first draft. DAP, RW, EF, DJ, and PR provided input. RW revised the draft, following referees' comments. ICM is guarantor.

Funding: None

Competing interests: DAP is a member of the team developing the personal qualities assessment.

1 James W, Hawkins C. Assessing potential: the development of selection procedures for the Oxford medical course. Oxford Rev Educ 2004;30:24155 .

2 Brown P. Admissions testing for entry to medicine. 01: the newsletter of LTSN-01 2004;No 6:27. www.ltsn-01.ac.uk (accessed 6 Jan 2005)
3 Admissions to Higher Education Steering Group. Fair admissions to higher education: recommendations for good practice. Nottingham: Department for Education and Skills Publications, 2004. www.admissions-review.org.uk (accessed 6 Jan 2005).

4 Bekhradnia B, Thompson J. Who does best at university? London: Higher Education Funding Council England, 2002. www.hefce.ac.uk/ Learning/whodoes (accessed 6 Jan 2005).

5 Choppin BHL, Orr L, Kurle SDM, Fara P, James G. The prediction of academic success. Slough: NFER Publishing, 1973.

6 James D, Chilvers C. Academic and non-academic predictors of success on the Nottingham undergraduate medical course 1970-1995. Med Educ on the Nottingham

7 Lumb AB, Vail A. Comparison of academic, application form and social factors in predicting early performance on the medical course. Med Educ 2004;38:1002-5

8 Ferguson E, James D, Madeley L. Factors associated with success in medical school and in a medical career: systematic review of the literature. BMJ 2002;324:952-7.

9 Deary IJ. Differences in mental abilities. BMJ 1998;317:1701-3.

10 Montague W, Odds FC. Academic selection criteria and subsequent performance. Med Educ 1990;24:151-7.

11 McManus IC, Richards P. Prospective survey of performance of medical students during preclinical years. BMJ 1986;293:124-7.

12 Curriculum, evaluation, and management centre. A-level update. www.cemcentre.org/recenttopics/alevelupdate/default.asp (accessed 6 Jan 2005).

13 Grey MR, Pearson SA, Rolfe IE, Kay FJ, Powis DA. How do Australian doctors with different pre-medical school backgrounds perform as interns? Educ Health 2001;14:87-96.

14 McManus IC, Smithers E, Partridge P, Keeling A, Fleming PR. A levels and intelligence as predictors of medical careers in UK doctors: 20 year prospective study. BMJ 2003;327:139-42.

15 Ackerman PL. A theory of adult intellectual development: process, personality, interests and knowledge. Intelligence 1996;22:227-57.

16 Perkins D, Tishman S, Ritchart R, Donis K, Andrade A. Intelligence in the wild: a dispositional view of intellectual traits. Educ Psychol Rev 2000;12:269-93.

17 Giddens J, Gloackner GW. The relationship of critical thinking to performance on the NCLEX-RN. J Nurs Educ 2005;44:85-9.

18 Pithers RT, Soden R. Critical thinking in education: a review. Educ Res 2000;42:237-49

19 Grav SA, Deem LP, Straja SR. Are traditional cognitive tests useful in predicting clinical success? J Dent Educ 2002;66:1241-5.

20 Ferguson E, James D, O'Hehir F, Sanders A. A pilot study of the roles of personality, references and personal statements in relation to performance over the 5 years of a medical degree. BMJ 326;2003:429-31.

21 Department of Health. Medical schools: delivering the doctors of the future. London: DoH Publications, 2004

22 Working group on 14-19 reform. 14-19 Curriculum and qualifications reform: final report of the working party on 14-19 reform [the Tomlinson report]. Nottingham: Department for Education and Skills Publications, 2004.

23 Lievens F, Coetsier P. Situational tests in student selection: an examination of predictive validity, adverse impact and construct validity. Int J Sel Assess 2002;10:245-57.

24 McManus IC, Vincent CA. Selecting and educating safer doctors. In: Vincent CA, Ennis M, Audley RJ, eds. Medical accidents. Oxford: Oxford University Press, 1993:80-105.

25 University of Cambridge Local Examinations Syndicate. FAQs on BMAT/TSA: "How do you know the tests are any good?" http:/ bmat.ucles-red.cam.ac.uk/background.html (accessed 25 Mar 2005).

(Accepted 6 June 2005)

\title{
Commentary: The benefits of aptitude testing for selecting medical students
}

Sandra Nicholson

The A level is the most common tool for assessing school leavers applying for higher education, including medicine. If medical school outcome is accurately predicted by A level grades, as described by McManus et al, ${ }^{1}$ what place, if any, do aptitude tests have in the selection of medical students?

Applications for medical school from appropriately highly qualified candidates have increased year on year ${ }^{2}$ until it has become increasingly difficult to discriminate between candidates with similar A level performance. Most medical schools wish to select future doctors using non-cognitive attributes alongside A levels, but procedures, such as interviewing, are time consuming and labour intensive. An urgent need is to reduce the number of candidates by initial screening that is appropriate, fair, and transparent but also gives added value to the process.

A further important reason for considering such testing initiatives is the concern that some groups are underrepresented in medicine because A level grades reflect educational background and social class. ${ }^{3}$ Additional tests that can show intellectual ability or aptitude rather than achievement may be a valuable means to widen participation. These tests-some without undue reliance on a heavy science background-may be a useful adjunct to A levels where candidates offer a variety of
Institute of Health Sciences Education, Queen Mary's School of Medicine and Dentistry, London E1 4NS Sandra Nicholson associate dean for admissions

s.nicholson@ qmul.ac.uk 
subjects from different examining boards or offer non-traditional qualifications.

Attributes such as general mental ability, critical thinking, problem solving, communication skills, empathy, psychological robustness, and integrity are some of the commonly cited required qualities of medical students. Aptitude tests such as the biomedical admissions test (BMAT), the medical school admissions test (MSAT), and the graduate medical school admissions test (GAMSAT) define intellectual ability in terms of critical reasoning and problem solving; examining a candidate's understanding of interpersonal issues and written communication. The personal qualities assessment test (PQA) assesses verbal, numerical, and spatial reasoning by its mental agility test, contains a personality inventory, and has an ethical reasoning paper. These tests aim to assess more than intellectual ability and have added value alongside A levels assessing some of the desirable non-cognitive characteristics in potential medical students.

To be defensible a selection method must be reliable within and across successive cohorts of applicants. It must select on the basis that it claims to test (that is, have construct validity) and it should predict the eventual performance of the potential doctor who is selected.

The personal qualities assessment test has been shown to distinguish candidates on the basis of cognitive function and personality independent of social class and schooling. The reliability and validity of the test has been documented, but the long term predictive value of performance as a doctor is under investigation. ${ }^{4}$ The biomedical admissions test and medical school admissions test have high face validity and allow differentiation between candidates without further inflation of A level grades. Although experience in the United Kingdom, Australia, and New Zealand is positive further validated data are needed to confirm that these tests successfully predict long term outcomes.

No one is advocating the abandonment of A levels in the selection of medical students. It is timely, however, to develop and evaluate selection methods that may be useful adjuncts in a holistic selection process that is fair, transparent, and accountable both to applicants and to their future patients. ${ }^{5}$

\section{Funding: None.}

Competing interests: $\mathrm{SN}$ is a member of the national working party of medical schools that has convened to examine the role of aptitude testing in undergraduate medical student selection.

1 McManus IC, Powis DA, Wakeford R, Ferguson E, James D, Richards P. Intellectual aptitude tests and A levels for selecting UK school-leaver entrants for medical school. BMJ 2005;331:555-9.

2 Department of Health. Medical schools: delivering the doctors of the future. London: $\mathrm{DoH}, 2004$.

3 Archer L, Hutchins M, Ross A, Leathwood C, Gilchrist R, Phillips D. Higher education and social class: issues of exclusion and inclusion. London: RoutledgeFalmer, 2003.

4 Lumsden MA, Bore M, Millar K, Jack R, Powis D. Assessment of personal qualities in relation to admission to medical school. Med Educ 2005;39: $258-65$

5 Schwartz S. Admissions to Higher Education Steering Group. Fair admissions to higher education: recommendations for good practice. Admissions to Higher Education, 2004. www.admissions-review.org.uk (accessed 26 Aug 2005).

\section{Transformational leadership}

A recent editorial on clinical leadership by Sisse Olsen and myself (BMJ 2005;330:1219-20) has led to my being asked how transformational leadership might affect clinical practice. Perhaps a clinical story might help.

One Sunday afternoon, a decade ago, I slipped into the hospital to ensure that a patient with severe acute ulcerative colitis was making satisfactory progress on conventional medical treatment. He was doing well. His abdomen was no longer tender, his pulse rate was back to normal, and he was feeling hungry.

As I was leaving the ward, a junior staff nurse, who I did not recognise, touched my arm and asked, "Dr Neale, would you see a patient for me?"

I guess that, with my mind elsewhere, I hesitated momentarily before saying, "Of course," and turned to go with her.

It was her turn to hesitate: "But she is not one of yours, and she was seen by the 'medical on call' at lunch-time."

"So ..."

She led me to a woman in her 70 s who was semiconscious but restless. She had been admitted a few days previously with a stroke. "It just that she is passing so little urine," explained the nurse. "The SHO said that he thought that she was dehydrated and that I should turn up the drip. I am just not sure that is right. In the bag is all the urine she has passed today."

A urinary catheter was attached to a bag that contained 200-300 ml of murky orange-brown fluid. The cause of the limited urine output seemed reasonably obvious to me, but I couldn't resist the temptation to go into teaching mode. Together, we traced the pathway of the fluid being infused to that appearing in the bag. Then I asked the nurse to lay her hand on the abdomen. As her hand came up against the fundus of a distended bladder, her eyes danced: "The catheter must be blocked."

"OK. Would you care to lay up a trolley for catheterisation? Small gloves and don't forget the incontinence pads, a large kidney dish, and a jug." Back she came with the trolley. "Now you scrub and glove up, and I will assist." And so this nurse came to undertake her first catheterisation of bladder-and saw her patient relax into somnolence.

That nurse had been the leader. For her, the patient's wellbeing came first, and, as a result, she was prepared to break the traditional hierarchy of care. That is what transformational leadership is about: it motivates clinical staff to think and empowers them to enhance patient care. It has been widely applied in the management of effective businesses and needs to be encouraged in hospital practice.

Graham Neale visiting professor, Clinical Safety Research Unit, Imperial College, St Mary's Hospital, London (g.neale@ic.ac.uk)

We welcome articles up to 600 words on topics such as A memorable patient, $A$ paper that changed my practice, $M y$ most unfortunate mistake, or any other piece conveying instruction, pathos, or humour. Please submit the article on http://submit.bmj.com Permission is needed from the patient or a relative if an identifiable patient is referred to. We also welcome contributions for "Endpieces," consisting of quotations of up to 80 words (but most are considerably shorter) from any source, ancient or modern, which have appealed to the reader. 